\title{
Gestión de la información en la criminología y criminalística en la era digital ${ }^{1}$
}

\section{Criminology and criminaliste's information management in the digital age}

\author{
Wael Sarwat Hikal Carreón ${ }^{1}$
}

\begin{abstract}
${ }^{1}$ Este artículo se suscribe en el proyecto doctoral "Estudio de Pertinencia de los Proyectos de Formación y Ejercicio Profesional de los Criminólogos", realizado en la Facultad de Filosofía y Letras de la Universidad Autónoma de Nuevo León, México. Financiación por el Consejo Nacional de Ciencia y Tecnología.

* Facultad de Filosofía y Letras, Universidad Autónoma de Nuevo León. Correo wael.hikalcrr@uanl.edu.mx. Orcid https://orcid.org/0000-0003-1278-567X
\end{abstract}

\section{DOI: https://doi.org/10.46589/rdiasf.vi36.416}

Recibido 26 de agosto 2021.

Aceptado 30 de septiembre 2021

Publicado 01 de noviembre 2021

\section{Resumen}

Estamos en la época de transformación, estamos de paso en un momento en que de la producción, se empoderó la información, es la era de oro de la informática. Esto puede aprovecharse para el acceso a la información, así como para su divulgación. Lo anterior puede aprovecharse para el aprendizaje continuo en criminología y criminalística. No es en las redes digitales donde logrará su experiencia o aprendizaje, estas no son centros universitarios, sino las instituciones formales para ello, y el campo de estudio es el área donde a través de sus sentidos podrá construir la realidad. El presente se divide en tres secciones, la primera, una generalización de preferencias de búsqueda de información en redes digitales, donde se hacen críticas sobre el uso en estos para proponer la mejor utilización encaminada a encontrar fuentes de información formales. La segunda parte es a la investigación y generación de conocimiento aprovechando lo digital y potencializando lo gratuito para consultar o desarrollar conocimiento; también se hace

\footnotetext{
${ }^{1}$ Este artículo se suscribe en el proyecto doctoral "Estudio de Pertinencia de los Proyectos de Formación y Ejercicio Profesional de los Criminólogos", realizado en la Facultad de Filosofía y Letras de la Universidad Autónoma de Nuevo León, México. Financiación por el Consejo Nacional de Ciencia y Tecnología.
} 
una propuesta de actitud profesional respecto lo que se comparte en redes, docencia y trabajo en equipo. Finalmente, se presentan plataformas dónde sí y no buscar información en materia criminal.

Palabras clave: Gestión de la información; Información y comunicación; Medios digitales.

\begin{abstract}
We are in the time of transformation, we are passing through a time when production, information was empowered, is the golden age of computing. This can be used for access to information as well as for its disclosure. This can be used for continuous learning in criminology and criminalistic. It is not in digital networks where you will achieve your experience or learning, these are not university centers, but the formal institutions for it, and the field of study is the area where through your senses you can build reality. The present is divided into three sections, the first, a generalization of information search preferences in digital networks, where criticism is made about the use in these to propose the best use aimed at finding formal sources of information. The second part is research and knowledge generation taking advantage of digital and potentializing the free to consult or develop knowledge; there is also a proposal for a professional attitude towards what is shared in networks, teaching and teamwork. Finally, platforms are presented where yes and do not seek information on criminal matters.
\end{abstract}

Keywords: Digital media; Information management; Information and communication.

\title{
Introducción
}

Si la tendencia de hoy para las nuevas generaciones y las anteriores que se van adaptando a estas, es lo digital, debe aprovecharse ello, estamos en una época donde se tiene acceso a infinidad de contenidos para aprendizaje, múltiples plataformas donde se depositan documentos, videos, audios, imágenes, etcétera, que son fuente de aprendizaje, pero pareciera que se desborda la ignorancia con contenidos absurdos, chismes, chistes, escándalos, medio espectacular, 
influenciadores, donde los conocimientos científicos quedan desestimados y desligitimizados por los hoy empoderados líderes de tendencias opuestas al desarrollo cultural, tergiversando el saber científico por conocimiento vulgar, con excusas de crear un saber digerible de fácil acceso a las generalidades (Lyotard, 1991).

Con el acceso a esos cientos de documentos (libros, artículos, capítulos, informes, reportes, estadísticas, etcétera), se puede llegar a hacer un análisis de las bibliografías que existen (Lyotard, 1991), con ese ejercicio se permite encontrar posturas, tendencias, áreas por explorar, desarrollar, hacer crecer, en ello consistiría una revisión bibliográfica. La clave está en encontrar los sitios idóneos para localizar esa información, no son las redes digitales los medios para buscar y fiarse de la información que se difunde; es decir, no se puede dar del todo válido una argumentación extraída de redes, sino como un vínculo o complemento que se podrá robustecer consultando a las fuentes directas, no precisamente con el estudio de caso, sino con la fuente institucional o de autoría de la información.

La calidad no se mide por likes, ni cantidad de seguidores, ni reacciones. En algún tiempo, se criticaba a Wikipedia por ser referente de muchos trabajos, pero si se revisa, lo que en ella se publica tiene bibliografía, no es que aquí se afirme la certeza de sus contenidos, puesto que no es sabido que tenga evaluadores académicos de contenidos, pero al notar sus bibliografías, se puede corroborar la información, ampliarla, lo mismo en Facebook, Twitter, etcétera, ir en búsqueda de más datos, que permitan probar. No es del todo la red, la mala, sino la función que los usuarios les den.

Se está en una época que a través de los dispositivos móviles y electrónicos en general, tal vez es cuando más se ha podido escribir o textear, se transmite mucha información a través de las redes digitales, en mesajeros o en grupos de WhatsApp se envían documentos enteros incluso, se recomparten, distribuyen, analizan, se transmiten tareas, imágenes y demás, pasó de darle un uso popular a sectorizarse en intereses particulares atendiendo a demandas profesionales o laborales. Es entonces, que podría aprovecharse esas herramientas, así como canalizar todo el texteo a producir información útil, sistematizar (con parámetros de método) ideas, experiencias y compartirlas, más que compartir estados de ánimo, alimentos, imágenes eróticas, vídeos caseros, memes, etcétera. 
En el ámbito forense y preventivo-criminal, las redes se ven congestionadas de contenidos de usuarios, recompartidos y reacciones tanto inútiles, esto afecta la legitimidad de la criminología y criminalística, posiblemente las víctimas de delitos o los encargados de la seguridad, si acuden a redes en búsqueda de perfiles útiles, no encuentren positivo el uso de memes, o la explotación histriónica por parte de los criminólogos y criminalistas.

Si el uso de lo anterior no es adecuado y con reflexión dará un resultado de bajo impacto. Por ello, la investigación ha de ser un movimiento constante que permita entender, construir los escenarios sociales, sus manifestaciones particulares, y responder a inquietudes sobre problemas (Amigeiras, 2006). La investigación en general, pero aquí en materia criminal debe seguir la ruta de comprender fenómenos, construirlos, explicarlos y buscar soluciones. El estudiante debe salir al campo y con observación participativa explorar y conocer, encontrar los códigos de la sociedad, y comenzar a adaptar la teoría que escucha en las aulas en contraste con su entorno.

No es en las redes digitales donde logrará su experiencia o aprendizaje, estas no son centros universitarios, sino las instituciones formales para ello, y el campo de estudio es el área donde a través de sus sentidos podrá construir la realidad. Es tal vez inevitable el dedicar horas de la vida a lo digital, pero en ese caso, hay que aprovechar las miles de revistas académicas y científicas de acceso abierto, los cursos en línea de calidad (no organizaciones fraudulentas). En el modo negativo, las redes digitales limitan la interacción, y la saturación de contenidos, entorpece, las redes verdaderamente sociales, implican relaciones con otras personas, grupos, instituciones, movimientos, tendencias (Mallimaci y Giménez Béliveau, 2006).

Estamos en la época de transformación, estamos de paso en un momento en que de la producción, se empoderó la información, es la era de oro de la informática. Esto puede aprovecharse para el acceso a la información, así como para su divulgación. También estamos en la fase en que la economía se basa en la informática, el desarrollo científico y tecnológico se lleva de una manera avanzada y creciente no antes vista de tal modo, la comunicación digital ha agilizado y apresurado este proceso. Anteriormente, no hace mucho, las comunicaciones eran por teléfono, llamadas de larga distancia, envío de paquetes por correo postal, esperas prolongadas 
para recibir la información, los vídeos eran limitados, hoy, esto y más cosas, están al acceso en un click.

Lo anterior puede aprovecharse para el aprendizaje continuo en criminología y criminalística, tenemos plataformas como YouTube donde se suben videos con contenidos de todo tipo, inútiles, estúpidos o formales, educativos, de aprendizaje, culturales, científicos. El criminólogo y criminalista deben ser selectivos con la calidad de dichos contenidos, no limitarse a un solo canal, expositor, organización, sino en todo caso, contrastar, verificar, comparar con otros canales y medios. Está Facebook live, donde se transmiten contenidos también, pero en el caso de estos campos de conocimiento, se han mal empleado para saciar el ego de criminfluencers para narrar sus estilos de vida parasitarios, es urgente reparar a estos gérmenes actores de la deslegitimación.

Un influenciador, genera seguidores, pero no es un científico, esto nace de un medio artístico, y los criminólogo y criminalistas, NO SON artistas, las carencias de atención, deben tratarse en el psicólogo, y no en imágenes eróticas, de morbo, videos en tiktok, o autoreferencias, donde se construye la imagen de ser cultos, líderes, millonarios, esto explícita su vacío intelectual y afectivo. La identificación con los grandes nombres y héroes de la historia como Lombroso, Freud, Sutherland, se hace más difícil si se apoya los criminfluenciadores, puesto que en lugar de tener estudiosos de teorías y proponer nuevas, tendremos creadores de contenidos chatarra, fáciles de digerir, pero la ciencia entre los profesionales tiene un lenguaje, y no ha de ser el vulgar. Para que un conocimiento sea validad como ciencia, requiere comprobar sus medios de prueba y que al debate, exista consenso para ser declarados falsos o verdaderos (Lyotard, 1991), estos llegan al estudiante y este a su vez "puede aprender y convertirse en un experto con idéntica competencia que su maestro" (Lyotard, 1991, p. 23).

\section{Aprovechamiento de lo digital para las investigaciones en materia criminal}

Las redes digitales no son solo un instrumento para la diversión, pueden ser bien empleadas con propósitos positivos. La sociedad espera de los profesionales un héroe social, que trabaje con un buen fin ético, político, que exista un lazo y compromiso social entre profesional- 
sociedad. La legitimación de la ciencia de la criminología y criminalística se logra cuando sus técnicas encuentran un fin útil para atender un problema, resolverlo o modificarlo, con acciones y propuestas, así como el desarrollo de conocimiento, el saber científico gira en torno a la investigación y la transmisión de conocimientos para otros profesionales, así como para la sociedad en general, quienes son los receptores; es decir pasa a una parte operativa. "Y, recíprocamente, se refuerzan tanto más las técnicas que se pueden disponer del saber científico y de la autoridad decisoria" (Lyotard, 1991, p. 38). La primicia es que el generar información es indispensable para potencializar la productividad, haciendo los datos útiles para la toma de decisiones.

El criminólogo y criminalista debe convertirse en un productor de conocimiento y desarrollador de técnicas, este es producido para ser vendido y consumido cuando encuentra utilizadores de aquel, innegable es que en sociedad se requiere estudiar y conocer el fenómeno criminal en sus expresiones para conocerlo, entenderlo, prevenirlo, atenderlo, rehabilitar a los sujetos actores del crimen, por un lado, por otro, investigar cómo se cometió un crimen para su reconstrucción y determinación de la actuación de los sujetos involucrados, por lo tanto hay demanda de expertos. De tal modo, la criminología y criminalística son necesarias en los sectores públicos y privados, que se beneficiaran de los resultados que sus profesionales aporten y que estos resultados permitan legitimar la ciencia y la profesión.

La era digital puede aprovecharse, somos privilegiados de estar en este momento, lo que no se tenía antes, donde las noticias tardaban meses o años en llegar, ahora llegan en segundos. Noticieros formales en línea, en televisión abierta, contrastado con otros, existen cantidades incontables de libros digitales, de revistas por miles en el mundo, revistas formales, no portales de redes digitales que disfrazan la calidad con la cantidad de seguidores. Existen instituciones públicas y privadas que realizan investigaciones, invierten en esta a largo plazo, sin esperar resultados inmediatos, se destina dinero a un "fondo perdido durante cierto tiempo para aumentar las oportunidades de obtener una innovación decisiva" (Lyotard, 1991, p. 37). Además emiten informes, investigaciones, estadísticas, parámetros, protocolos, etcétera, es ahí donde el criminólogo y criminalista pueden estar sumergidos, aprendiendo, ejerciendo para la justicia 
social, la actuación eficaz del sistema, desarrollar conocimiento de tal manera que su ciencia se convierta en fuerza de producción.

Si se registran las experiencias se deja constancia de lo vivido, trabajado, observado, atendido, teorizado o procurado como resuelto; es decir, se transforman en textos, con lo que se construye el conocimiento para la comprensión social de problemas, y que a su vez, sean herramienta para que otros conozcan, aprendan, implemente o innoven. Con el fin de que "ciertos aspectos de la transformación del saber y sus efectos sobre los poderes políticos y sobre las instituciones civiles" (Lyotard, 1991, p. 9) cambien y mejoren en la administración pública o en las empresas, o sector social.

\section{Pertinencia profesional de los criminólogos y criminalistas.}

Muchos retos sociales se avecinan, no podemos adivinar qué tipo de conductas criminales nuevas están por aparecer, los constructores de la criminología y criminalística de hace 100 años, no imaginaron las modalidades criminales que ahora ocurren, los actuales criminólogos y criminalistas, tal vez pueden imaginar que podrán agravarse situaciones, pero sin saber en específico qué modos. Con la creación de redes digitales, tal vez no se esperaba la aparición de El Blog del Narco para subir en una página web noticias, imágenes, videos de torturas, descuartizamientos, y que distan de ser lo que hace años cuando comenzaba el sitio, con la creación de Facebook, no se esperaría que en una transmisión en vivo, se disparará, hiriera o matará a personas en Nueva Zelanda.

Las nuevas técnicas digitales benefician como antes nunca, hoy es el acceso al mundo a través de dispositivos electrónicos, el acceso está abierto, hay que utilizarlo positivamente para la investigación (Chernobilsky, 2006). El uso de los dispositivos, permite al criminólogo y criminalista: Emplear herramientas para la búsqueda de información; localizar y consultar bases de datos (revistas, informes, libros).

La siguiente tabla se basa en la guía del investigador de Cram (como citó Tuhiwai Smith, 2011, p. 213), en la definición de la conducta del investigador, adaptada a la labor del criminólogo y criminalista en el uso de la información a la que tiene acceso, en referencia a 
restringir su publicación en medios digitales, así como también en su actuar con las personas que investiga.

Tabla 1. Algunas claves en el actuar del criminólogo y criminalista.

\begin{tabular}{|c|c|}
\hline $\begin{array}{l}\text { Respetar a las personas. No aprovecharse } \\
\text { de su cargo como "servidores públicos" de } \\
\text { cualquier nivel, como el término lo indica, } \\
\text { están al servicio de la sociedad, se deben a } \\
\text { esta y están para ella, por otro lado, si se } \\
\text { ocupan en el sector privado, por ningún } \\
\text { motivo, hacer público en redes digitales los } \\
\text { casos que aborden, imágenes, relatos, } \\
\text { videos, prácticas } \\
\text { capacitaciones que impliquen uso de } \\
\text { herramientas delicadas como armas. } \\
\text { Tampoco jugar con la cinta amarilla de } \\
\text { escena del crimen o mostrando sus huellas } \\
\text { dactilares, no mostrar autopsias o revelar los } \\
\text { diagnósticos de las personas involucradas o } \\
\text { mostrar información que es de uso } \\
\text { exclusivo. No tomar ventaja de los casos } \\
\text { para vender conferencias, cursos, prácticas, } \\
\text { etcétera. }\end{array}$ & $\begin{array}{l}\text { Mirar, escuchar, dar la cara. Si se trata de } \\
\text { entrevistas, interrogatorios (cuando sea } \\
\text { procedente), es importante prestar atención, } \\
\text { desarrollar la comprensión y facilitar el } \\
\text { habla. Ya sea con sospechosos, criminales o } \\
\text { víctimas, las habilidades de comunicación y } \\
\text { trasmisión de ideas, permitirán una mejor } \\
\text { obtención de información. }\end{array}$ \\
\hline $\begin{array}{l}\text { Compartir, ser generoso. No significa } \\
\text { compartir información en redes para } \\
\text { conocimiento y morbo de otros, sino que } \\
\text { indica que el criminólogo y criminalista sea } \\
\text { colaborativo en la investigación para que la }\end{array}$ & $\begin{array}{l}\text { Ser prudentes. No ostentarse con el } \\
\text { conocimiento, sin ser presumido, compartir } \\
\text { conocimiento para empoderar la } \\
\text { investigación y legitimar las técnicas de } \\
\text { búsqueda, análisis. No para acrecentarse a sí }\end{array}$ \\
\hline
\end{tabular}




\begin{tabular}{|l|l|}
\hline información fluya en diversos sentidos, ya & mismo, la profesión es un don, y este hay \\
sea con las personas que debe investigar o & que hacerlo crecer. \\
cuando se trate de enseñar y transmitir & \\
conocimientos, si es de sus experiencias, & \\
generalizar los casos para no ser indiscreto & \\
con las particularidades, o si se presentan & \\
casos, difuminar nombres, colonias, & \\
cambiarlos, discrecionarlos. & \\
\hline
\end{tabular}

Nota. Elaboración propia.

La criminología y criminalística se han convertido en profesiones y dieron lugar a instituciones donde son enseñadas (Zaffaroni, 1990), también donde son implementadas, la acumulación de los conocimientos lleva a nuevas investigaciones provocando un proceso acumulativo transmitido mediante la enseñanza pedagógica (aulas) y la técnica de implementación (sector social), creando puentes de conexión (Prawda y Flores, 2001). Las universidades son las encargadas de exponer aquellos conocimientos, generar nuevos y que aparezcan como fundamentos para la toma de decisiones y acciones, la ciencia sirve a los intereses de la sociedad civil, del estado y de la humanidad, como fin último práctico, esto hará legítimo el poder de acción de la criminología y criminalística.

Este empoderamiento no viene ligado a la proliferación de centros escolares si estos no toman para sí, la investigación científica, en caso contrario, se producen usurpaciones y crisis del desarrollo científico (Lyotard, 1991). "Así el incremento del poder, y su autolegitimación, pasa ahora por la producción, la memorización, la accesibilidad y la operacionabilidad de las informaciones" (Lyotard, 1991, p. 38).

\section{Dónde buscar la información correcta en materia criminal.}

Se cuentan con miles de revistas, directorios y plataformas donde se difunden artículos, libros, informes académicos, estadísticos, científicos, pero pareciera que el criminólogo y 
criminalista no están revisando donde deberían hacerlo, por el contrario, buscan en Facebook, hacen un foro de consulta para tareas, libros en PDF gratuitos, quien realice su investigación y sus fuentes de conocimiento son obtenidas de redes digitales. En la siguiente dirección https://portal.issn.org/ pueden introducirse palabras clave como: Seguridad pública, criminología, psicología criminal, victimología, forense, criminalística, entre otros, para que el buscador arroje los resultados de revistas legales, de entes institucionales y en gran mayoría de casos "gratuitas", para consultas, descarga, lectura.

Además de esto, basta con que el lector-investigador ponga en su buscador los términos: DOAJ, Scielo, Redalyc, Scopus, Dialnet, ResearchGate, y de estos, resultarán otros, para que de igual forma, coloque los términos y consulte información de mejor calidad. Utilizar también estos para publicar formalmente sus resultados de investigación; recuperar, editar, corregir la información; aprovechar las imágenes, vídeos, audios, películas como fuentes de datos; manejar estos para la recogida de información o su presentación (no para selfies, tiktoks, o memes), y facilita la escritura, permite su presentabilidad y organización, exposición, por ejemplo, buscar plantillas con diseños más elaborados. En ocasiones el criminólogo y criminalista actúa como un inútil incapaz de realizar búsquedas en páginas web, pero muy hábil para pasar su tiempo en Facebook, esta no es un centro universitario, ni biblioteca.

\section{Agradecimientos}

La realización del presente artículo es posible gracias al auspicio de la Facultad de Filosofía y Letras de la Universidad Autónoma de Nuevo León y al Consejo Nacional de Ciencia y Tecnología en el Programa de Posgrados de Calidad Nacional de Doctorado en Filosofía con Acentuación en Estudios de la Educación del Doctorado en Filosofía con Acentuación en Estudios de la Educación. Tesis "Estudio de Pertinencia de los Proyectos de Formación y Ejercicio Profesional de los Criminólogos”, bajo la dirección del Dr. Rogelio Cantú Mendoza. 


\section{Conclusiones}

Las redes digitales pueden ser aprovechadas útilmente para la búsqueda de información provechosa para el aprendizaje, extracción de datos estadísticos, reportes, investigaciones, libros, entre otros. El criminólogo y criminalista debe ser selectivo en la identificación de documentos, plataformas, etcétera, puesto que de la calidad de los contenidos se debe su argumentación profesional para el ejercicio. Por otro lado, el desarrollo científico es necesario para hacer crecer, empoderar, acumular y legitimar a la criminología y criminalística, con la creación de técnicas, su aplicación, investigación, poder de proposición encaminado al cambio social e institucional. Los objetivos anteriores se pueden lograr con la correcta búsqueda de información en los canales adecuados.

\section{Bibliografía}

Ameigeiras, A.R. (2006). El abordaje etnográfico en la investigación social. En I. Vasilachis De Gialdino (coord). Estrategias de Investigación Cualitativa. Gedisa, pp. 107-151.

Chernobilsky, L.B. (2006). El uso de la computadora como auxiliar en el análisis de datos cualitativos. En I. Vasilachis De Gialdino (coord). Estrategias de Investigación Cualitativa. Gedisa, pp. 239-273.

Denzin, N.K. y Lincoln, Y.S. (comps.) (2011). El Campo de la Investigación Cualitativa. Manual de Investigación Cualitativa. Volumen I. Editorial Gedisa.

Lyotard, J.F. (1991). La Condición Postmoderna. Editorial REI Argentina. https://www.uv.mx/tipmal/files/2016/10/J-F-LYOTARD-LA-CONDICION-

POSMODERNA.pdf

Mallimaci, F. y Giménez Béliveau, V. 2006. Historia de vida y métodos biográficos. En I. Vasilachis De Gialdino (coord). Estrategias de Investigación Cualitativa. Gedisa, pp. 175-212.

Prawda, J y Flores, G. (2001). México Educativo Revisitado. Reflexiones al Comienzo de un Nuevo Siglo. Editorial Océano de México. 
Tuhiwai Smith, L. (2006). Caminando sobre terreno resbaladizo. La investigación de los pueblos nativos en la era de la incertidumbre. En I. Vasilachis De Gialdino (coord). Estrategias de Investigación Cualitativa. Gedisa, pp. 190-230.

Zaffaroni, E.R. (1990). La enseñanza universitaria de la criminología en América Latina. Eguzkilore. Cuaderno del Instituto Vasco de Criminología. 3, 59-71. Recuperado de https://www.ehu.eus/documents/1736829/2164896/08+-

+La+ensenanza+universitaria+de+la+criminologia.pdf

\section{Cómo citar:}

Hikal Carreón, W. S. (2021). Gestión de la información en la criminología y criminalística en la era digital. Revista De Investigación Académica Sin Frontera: División De Ciencias Económicas Y Sociales, (36). https://doi.org/10.46589/rdiasf.vi36.416

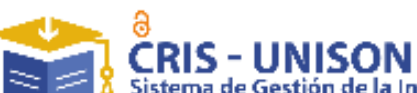

Sistema de Gestión de la Investigación

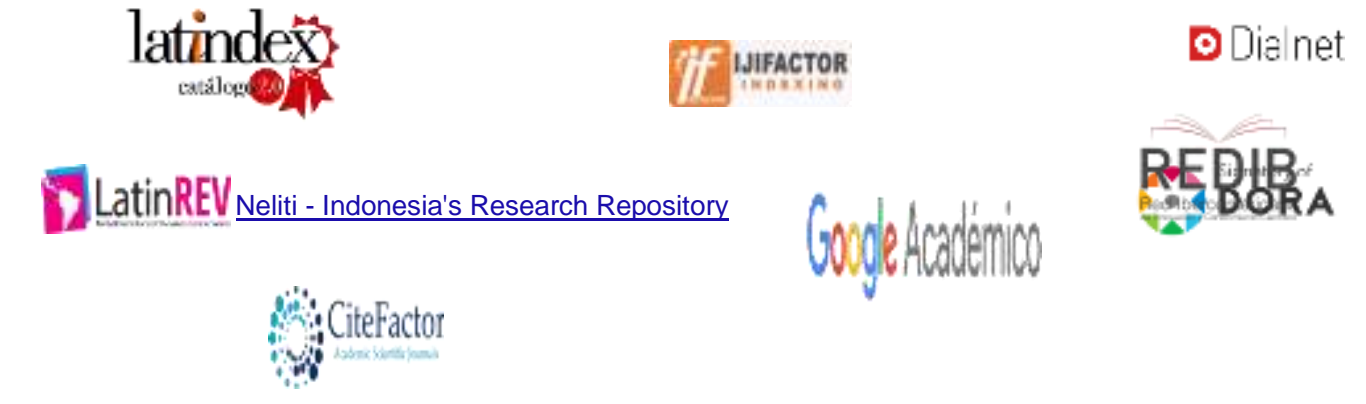

Cistema de Gestión de la investigación

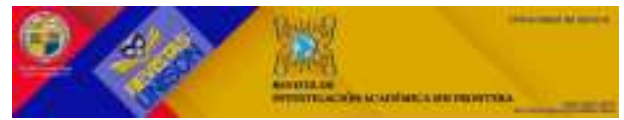

